\title{
Wheat dwarf India Virus and associated betasatellite infecting wheat in Pakistan
}

\author{
Jitendra Kumar ${ }^{1} \cdot$ Javed Ahmad $^{2} \cdot$ Muhammad Imtiaz $^{3} \cdot$ Shahryar F. Kianian $^{4}$ \\ Received: 25 October 2019 / Accepted: 2 March 2020 / Published online: 22 March 2020 \\ (C) This is a U.S. government work and not under copyright protection in the U.S.; foreign copyright protection may apply 2020
}

\begin{abstract}
Presence of Wheat dwarf India virus (WDIV) and Ageratum yellow leaf curl betasatellite (AYLCB) was confirmed using polymerase chain reaction and sequencing in wheat samples originating from Pakistan for the first time. However, no alphasatellites were detected from the analyzed samples. Both, WDIV and AYLCB were highly similar to their counterparts reported from wheat in India. The findings of this study suggest a strong association between WDIV and AYLCB. This is also the first report of a monocot infecting mastrevirus and the presence of a satellite in a monocot plant in Pakistan.
\end{abstract}

Keywords Geminiviridae · Mastrevirus · Betasatellite $\cdot$ WDIV and AYLCB

Members of the genus Mastrevirus (family Geminiviridae) are transmitted by leafhoppers and infect either dicot or monocot plants (Kraberger et al. 2013). Wheat dwarf India virus (WDIV) is a monocot infecting mastrevirus and has been reported to infect wheat in India (Kumar et al. 2012). Two alphasatellites (cotton leaf curl Multan alphasatellite; CLCuMA and guar leaf curl alphasatellite; GLCuA) and a betasatellite (Ageratum yellow leaf curl betasatellite; AYLCB) have been documented to be associated with WDIV and enhance virus accumulation and disease symptoms severity (Kumar et al. 2014a, b). Furthermore, the uniform presence of WDIV and associated alphasatellite and betasatellites were documented from several geographical regions in India (Kumar et al. 2015), advocating strong association between WDIV and the DNA satellites. Recently, another mastrevirus, Chickpea chlorotic dwarf virus (CpCDV)

Electronic supplementary material The online version of this article (https://doi.org/10.1007/s13314-020-00383-y) contains supplementary material, which is available to authorized users.

Shahryar F. Kianian

Shahryar.Kianian@ars.usda.gov

1 Department of Plant Pathology, University of Minnesota, St. Paul, MN, USA

2 Wheat Research Institute, AARI, Faisalabad, Pakistan

3 CIMMYT, Pakistan, NARC CSI Complex, Park Road, Islamabad, Pakistan

4 USDA-ARS Cereal Disease Laboratory, St. Paul, MN, USA was found associated with the DNA satellites, cotton leaf curl Multan betasatellite (CLCuMB) and CLCuMA, infecting spinach in Pakistan (Hamza et al. 2018). The associated betasatellite, CLCuMB, was documented to enhance the symptoms caused by CpCDV (Hamza et al. 2018).

The present study is based on a survey that was carried out across different geographical regions (Table 1) of Pakistan for investigating the presence of WDIV and associated DNA satellites. Leaf samples from 59 symptomatic wheat plants were collected during 2017-18 from commercial crops and research fields. The symptomatic plants showed dwarfing and/ or yellowing, similar to those previously reported in India by Kumar et al. (2012, 2014a). Young leaf samples were collected and stored in a tube with ethanol at room temperature for a week. Then the ethanol was decanted, and the dried leaf sample was stored in a deep freezer until further use. Total DNA was isolated from the dried leaf samples using a modified SDS method (Edwards et al. 1991) and used as template in polymerase chain reaction (PCR).

PCR amplifications were performed using total DNA as template and primers specific to WDIV and DNA satellites (Table 2). Fragments of $\sim 2.7$ and $\sim 1.3 \mathrm{~kb}$, the sizes expected for WDIV and betasatellite, respectively, were observed from the samples (Fig. 1A and B). Twenty-five out of the 59 samples tested positive for WDIV (Table 1). A total of 16 samples, of the 25 WDIV positive samples, tested positive for AYLCB (Table 1). However, the PCR reactions using a number of known (Bull et al. 2003; Kumar et al. 2010) and new primers (Table 2) for alphasatellite did not yield any fragment from any of the 59 samples. 
Table 1 Name and geographical coordinates of the sample collection locations

\begin{tabular}{|c|c|c|c|c|c|}
\hline Location & Latitude $(\mathrm{N})$ & Longitude (E) & Sample No. & WDIV* & AYLCB* \\
\hline AZRC, D.I. Khan & $31^{\circ} 53^{\prime}$ & $70^{\circ} 51^{\prime}$ & $1 \mathrm{a}$ & - & - \\
\hline AZRC, D.I. Khan & $31^{\circ} 53^{\prime}$ & $70^{\circ} 51^{\prime}$ & $1 \mathrm{~b}$ & MN240315 & MN240340 \\
\hline YARK, D.I. Khan & $32^{\circ} 06^{\prime}$ & $70^{\circ} 48^{\prime}$ & 3 & MN240316 & MN240341 \\
\hline Gul Imam, Tank & $32^{\circ} 17^{\prime}$ & $70^{\circ} 33^{\prime}$ & 5 & MN240317 & - \\
\hline Ghazni Khel, Lakki Marwat & $32^{\circ} 35^{\prime}$ & $70^{\circ} 45^{\prime}$ & 7 & - & - \\
\hline Sarai Gambila, Lakki Marwat & $32^{\circ} 73^{\prime}$ & $70^{\circ} 46^{\prime}$ & 11 & - & - \\
\hline Sarai Naurung, Bannu & $32^{\circ} 49^{\prime}$ & $70^{\circ} 46^{\prime}$ & 13 & - & - \\
\hline Near Central Jail, Bannu & $33^{\circ} 00^{\prime}$ & $70^{\circ} 42^{\prime}$ & $15 \mathrm{a}$ & MN240318 & MN240342 \\
\hline Nasir Abad, Karak & $33^{\circ} 01^{\prime}$ & $71^{\circ} 00^{\prime}$ & $15 \mathrm{~b}$ & MN240319 & - \\
\hline Tangori chowk, Karak & $33^{\circ} 06^{\prime}$ & $71^{\circ} 06^{\prime}$ & 17 & MN240320 & MN240343 \\
\hline Markaz, Karak & $33^{\circ} 07^{\prime}$ & $71^{\circ} 06^{\prime}$ & 19 & MN240321 & - \\
\hline Sur Gul, Kohat & $33^{\circ} 30^{\prime}$ & $71^{\circ} 23^{\prime}$ & 21 & - & - \\
\hline Khair Mato, Kohat & $33^{\circ} 30^{\prime}$ & $71^{\circ} 31^{\prime}$ & 23 & - & - \\
\hline Gombat, Kohat & $33^{\circ} 30^{\prime}$ & $71^{\circ} 39^{\prime}$ & 25 & - & - \\
\hline Khander, Kohat & $33^{\circ} 32^{\prime}$ & $71^{\circ} 50^{\prime}$ & 27 & - & - \\
\hline CCRI, Pirsabak, Nowshera & $34^{\circ} 00^{\prime}$ & $72^{\circ} 02^{\prime}$ & 29 & MN240322 & MN240344 \\
\hline Nasata, Charsada & $34^{\circ} 06^{\prime}$ & $71^{\circ} 48^{\prime}$ & 60 & MN240323 & MN240345 \\
\hline Bacha Khan University, Charsada & $34^{\circ} 07^{\prime}$ & $71^{\circ} 49^{\prime}$ & 69 & MN240324 & MN240346 \\
\hline Chota Lahore, Swabi & $34^{\circ} 00^{\prime}$ & $72^{\circ} 18^{\prime}$ & 72 & MN240325 & MN240347 \\
\hline Zaida, Swabi & $34^{\circ} 03^{\prime}$ & $72^{\circ} 29^{\prime}$ & 76 & - & - \\
\hline Hamlet Topi, Swabi & $34^{\circ} 03^{\prime}$ & $72^{\circ} 38^{\prime}$ & 78 & - & - \\
\hline Hamlet Topi, Swabi & $34^{\circ} 03^{\prime}$ & $72^{\circ} 38^{\prime}$ & 82 & MN240326 & MN240348 \\
\hline Saleem Khan, Swabi & $34^{\circ} 08^{\prime}$ & $72^{\circ} 26^{\prime}$ & 85 & MN240327 & MN240349 \\
\hline Munsabdar, Swabi & $34^{\circ} 12^{\prime}$ & $72^{\circ} 21^{\prime}$ & 87 & MN240328 & - \\
\hline Shahbaz Ghari, Mardan & $34^{\circ} 13^{\prime}$ & $72^{\circ} 09^{\prime}$ & 88 & MN240329 & MN240350 \\
\hline Zando Dheri, Mardan & $34^{\circ} 13^{\prime}$ & $72^{\circ} 06^{\prime}$ & 89 & MN240330 & - \\
\hline Jabba, Mardan & $34^{\circ} 10^{\prime}$ & $72^{\circ} 06^{\prime}$ & 92 & - & - \\
\hline Jabba, Mardan & $34^{\circ} 10^{\prime}$ & $72^{\circ} 06^{\prime}$ & 94 & MN240331 & - \\
\hline Khao, Mardan & $34^{\circ} 07^{\prime}$ & $72^{\circ} 03^{\prime}$ & 95 & MN240332 & MN240351 \\
\hline Rashaka, Mardan & $34^{\circ} 06^{\prime}$ & $72^{\circ} 01^{\prime}$ & 97 & MN240333 & - \\
\hline NARC, Islamabad & $33^{\circ} 40^{\prime}$ & $73^{\circ} 7^{\prime}$ & $801 \mathrm{~A}$ & MN240334 & MN240352 \\
\hline NARC, Islamabad & $33^{\circ} 40^{\prime}$ & $73^{\circ} 7^{\prime}$ & $801 \mathrm{~B}$ & - & - \\
\hline NARC, Islamabad & $33^{\circ} 40^{\prime}$ & $73^{\circ} 7^{\prime}$ & $801 \mathrm{C}$ & - & - \\
\hline NARC, Islamabad & $33^{\circ} 40^{\prime}$ & $73^{\circ} 7^{\prime}$ & $801 \mathrm{D}$ & MN240335 & MN240353 \\
\hline NARC, Islamabad & $33^{\circ} 40^{\prime}$ & $73^{\circ} 7^{\prime}$ & $801 \mathrm{E}$ & - & - \\
\hline NARC, Islamabad & $33^{\circ} 40^{\prime}$ & $73^{\circ} 7^{\prime}$ & $801 \mathrm{~F}$ & MN240336 & - \\
\hline NARC, Islamabad & $33^{\circ} 40^{\prime}$ & $73^{\circ} 7^{\prime}$ & $801 \mathrm{G}$ & MN240337 & MN240354 \\
\hline NARC, Islamabad & $33^{\circ} 40^{\prime}$ & $73^{\circ} 7^{\prime}$ & $801 \mathrm{H}$ & & - \\
\hline NARC, Islamabad & $33^{\circ} 40^{\prime}$ & $73^{\circ} 7^{\prime}$ & $801 \mathrm{I}$ & MN240338 & - \\
\hline NARC, Islamabad & $33^{\circ} 40^{\prime}$ & $73^{\circ} 7^{\prime}$ & $801 \mathrm{~J}$ & - & - \\
\hline Jhelum river bank & $31^{\circ} 99^{\prime}$ & $72^{\circ} 34^{\prime}$ & P62 & - & - \\
\hline Langar wala toll plaza near Jhelum river & $31^{\circ} 99^{\prime}$ & $72^{\circ} 34^{\prime}$ & P63 & - & - \\
\hline Langar wala toll plaza near Jhelum river & $31^{\circ} 99^{\prime}$ & $72^{\circ} 34^{\prime}$ & P64 & - & - \\
\hline Chenab river bank & $31^{\circ} 61^{\prime}$ & $72^{\circ} 58^{\prime}$ & P65 & MN240339 & MN240355 \\
\hline Rahmoana, Faisalabad & $31^{\circ} 42^{\prime}$ & $72^{\circ} 75^{\prime}$ & P66 & - & - \\
\hline Field area of NARC, Islamabad & $33^{\circ} 40^{\prime}$ & $73^{\circ} 7^{\prime}$ & $\mathrm{P} 67$ & - & - \\
\hline Field area of NIGAB, Islamabad & $33^{\circ} 67^{\prime}$ & $73^{\circ} 12^{\prime}$ & P68 & - & - \\
\hline Field area of CDRI, Islamabad & $33^{\circ} 67^{\prime}$ & $73^{\circ} 13^{\prime}$ & P69 & - & - \\
\hline Field area of CDRI, Islamabad & $33^{\circ} 67^{\prime}$ & $73^{\circ} 13^{\prime}$ & P70 & - & - \\
\hline
\end{tabular}


Table 1 (continued)

\begin{tabular}{|c|c|c|c|c|c|}
\hline Location & Latitude $(\mathrm{N})$ & Longitude (E) & Sample No. & WDIV* & AYLCB* \\
\hline Field area of ARS, Swabi & $34^{\circ} 12^{\prime}$ & $72^{\circ} 50^{\prime}$ & P71 & - & - \\
\hline Field area of ARS, Swabi & $34^{\circ} 12^{\prime}$ & $72^{\circ} 50^{\prime}$ & $\mathrm{P} 72$ & - & - \\
\hline Field area of NIFA, Peshawar & $34^{\circ} 01^{\prime}$ & $71^{\circ} 71^{\prime}$ & $\mathrm{P} 73$ & - & - \\
\hline Field area of NIFA, Peshawar & $34^{\circ} 01^{\prime}$ & $71^{\circ} 71^{\prime}$ & P74 & - & - \\
\hline Field area of CCRI, Pirsabak & $34^{\circ} 01^{\prime}$ & $72^{\circ} 04^{\prime}$ & P75 & - & - \\
\hline Field area of CCRI, Pirsabak & $34^{\circ} 01^{\prime}$ & $72^{\circ} 04^{\prime}$ & P76 & - & - \\
\hline Field area of CDRI, Islamabad & $33^{\circ} 67^{\prime}$ & $73^{\circ} 13^{\prime}$ & P77 & - & - \\
\hline Field area of NIFA, Peshawar & $34^{\circ} 01^{\prime}$ & $71^{\circ} 71^{\prime}$ & P78 & - & - \\
\hline Field area of TARNAB, Peshawar & $34^{\circ} 01^{\prime}$ & $71^{\circ} 70^{\prime}$ & P79 & - & - \\
\hline Field area of CCRI, Pirsabak & $34^{\circ} 01^{\prime}$ & $72^{\circ} 04^{\prime}$ & P80 & - & - \\
\hline
\end{tabular}

*Absence of WDIV and betasatellite are shown by (-), whereas, the samples positive for WIDV and betsatellite show the GenBank accession numbers of a WDIV and AYCB sequence submitted to database

The PCR products obtained with the primers specific for WDIV and AYLCB, respectively, were cloned in pJET1.2 cloning vector (Thermo Scientific). Three positive clones for WDIV from each of the 25 samples were selected for partial sequencing from both ends using pJET1.2 forward and reveres primer to confirm the identity, which was followed, by sequencing one clone from each of the 25 samples in entirety. Similarly, three positive clones for AYLCB from each of the 16 samples were sequenced partially to confirm the identity. One confirmed clone from each of the 16 AYLCB positive samples were sequenced in entirety. The viral and satellite sequences were assembled using CAP3 program (Huang and Madan 1999). Multiple sequence alignments were done by MUSCLE to construct neighbor-joining phylogenetic tree using the Molecular Evolutionary Genetics Analysis software, MEGA7 (Kumar et al. 2016).

The virus genomes amplified from all of the plant samples were 2783 bp long and showed sequence identities of $99 \%$ with WDIV reported previously (Kumar et al. 2012, 2014a, b; 2015). Based on the mastrevirus species and strain demarcation thresholds of $>78 \%$ and $>94 \%$ identity, respectively (Muhire et al. 2013) the viral genomes detected under study are isolates of WDIV. Phylogenetic analysis showed that the
Table 2 List of primers used in this study

\begin{tabular}{lll}
\hline Name of primers & Nucleotide sequence (5'-3') & Reference \\
\hline WDVKF & GGTACCTGAAGGTTGAAGACGA & This work \\
WDVKR & GGTACCGCAGTAATAACTGCTT & This work \\
WDVHF & AAGCTTAGGAAGCTCCCGGT & This work \\
WDVHR & AAGCTTGGTCGCCGATCCTTT & This work \\
Beta01 & GAAACCACTACGCTACGCAGC & Kumar et al. 2010 \\
Beta04 & ACCCTCCCAGGGGTACACACCG & Kumar et al. 2010 \\
Nanofor & AAGTGGGTCCTGGTTCTA & Kumar et al. 2010 \\
Nanorev & CTGTACAGGTCTCTGGC & Kumar et al. 2010 \\
DNA101 & CTGCAGATAATGTAGCTTACCAG & Bull et al. 2003 \\
DNA102 & CTGCAGATCCTCCACGTGTATAG & Bull et al. 2003 \\
Alpha1F & GTAATTCGAAGTCCGGTGAGA & This work \\
Alpha1R & AGATTCTCGTTGTCGTCGTT & This work \\
Alpha2F & ACGAAGCTCGGGATTACTGTA & This work \\
Alpha2R & CGGTCTTACGCGCACGTTGTT & This work \\
Alpha3F & GACGACTCGACGACGCCACT & This work \\
Alpha3R & GGCGACTCTTCTTCCTGCCA & This work \\
AlphaPstF & CTGCAGATAAVGTWYVRTWD & This work \\
AlphaPstR & CTGCAGATCCWCKKSMMMWW & This work \\
\hline
\end{tabular}

*Underlined nucleotides represent restriction sites 

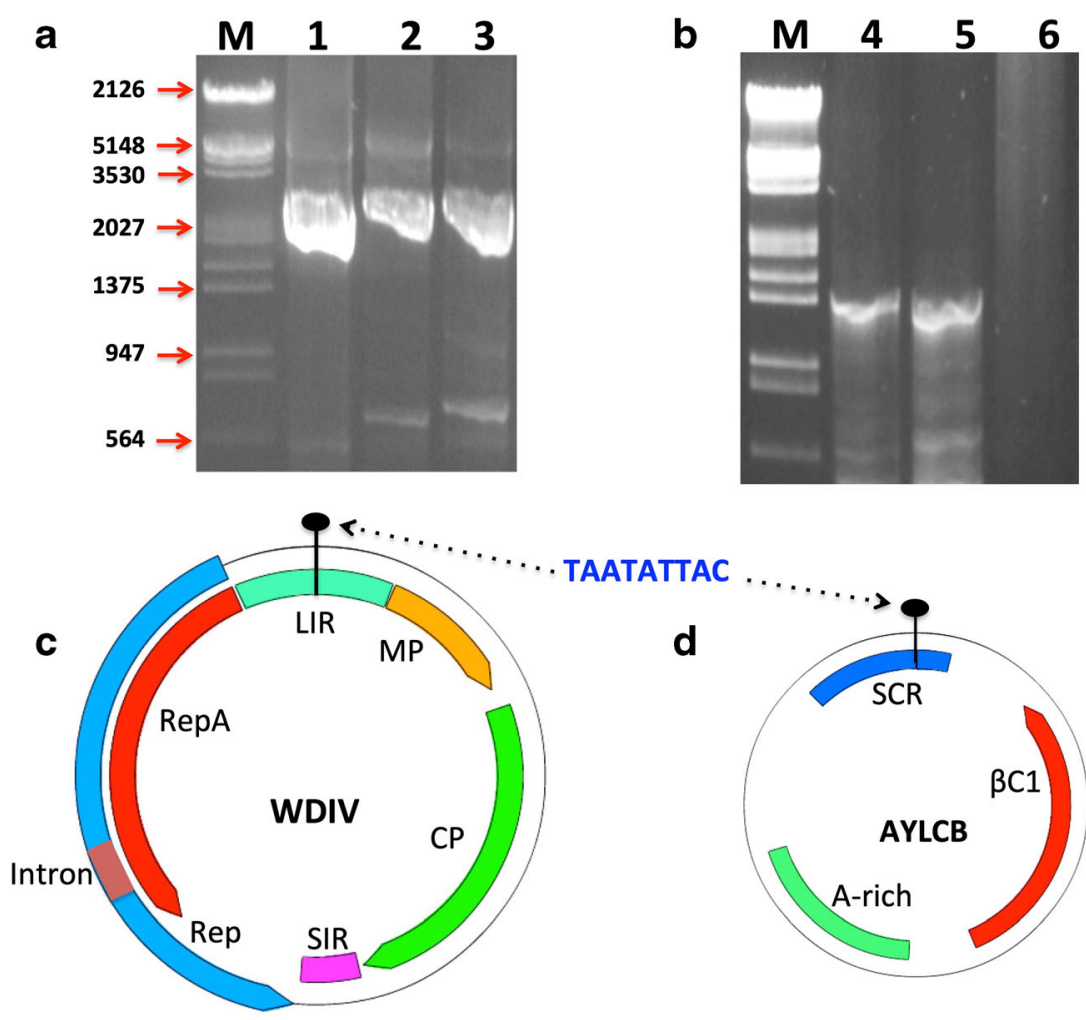

Fig. 1 Detection of the virus and the satellite DNAs in symptomatic plant samples. PCR amplicon of $\sim 2.7 \mathrm{~kb}$ representing the genome size of WDIV (A). PCR products of the betasatellite showing amplicon of $\sim 1.3 \mathrm{~kb}(\mathbf{B})$. Lanes 1 and 4, 2 and 5, 3 and 6 represents PCR amplicons from sample number 1b, 3 and 5, respectively, and M is EcoRI/HindIIIdigested XDNA. Genomic organization of WDIV (C) and AYLCB (D). The positions of coat protein (CP), movement protein (MP), replication-

new sequences clustered with the previously reported WDIV isolates (Supplementary Fig. 1).

Open reading frames (ORFs) of the WDIV clones were determined using ORF finder tool (https://www. ncbi.nlm.nih.gov/orffinder/). The analysis showed four potential ORFs, two [V1 (CP) and V2 (MP)] on virion sense strand and two [C1 (RepA) and $\mathrm{C} 1: \mathrm{C} 2(\mathrm{Rep})]$ on complementary sense strand (Fig. 1C), conserved in sequence and position between all of the clones and also with the previously reported WDIV. The virion and complementary sense ORFs were separated by small intergenic region (SIR) and large intergenic region (LIR). The LIR harbored a predicted stem-loop structure with the nonanucleotide sequence TAATATTAC as the origin of viral DNA replication (Fig. 1C). The complete nucleotide sequence of one clone from each sample was submitted to GenBank database under accession numbers MN240315 to MN240339 (Table 1).

Betasatellites size ranged from 1364 to $1367 \mathrm{bp}$ and showed sequence identities of $99 \%$ with AYLCB reported previously from wheat (Kumar et al. 2014a, b, and 2015). In phylogenetic tree, all of the 16-betasatellite sequences clustered together with previously reported

associated protein (Rep), replication-associated protein A (RepA), and $\beta C 1$ genes are shown on the map. Other features, including the intron in the Rep gene, the large intergenic region (LIR), the small intergenic region (SIR), the A-rich region and the satellite conserved region (SCR), are also shown. The position of nonanucleotide sequence, TAATATTAC, in WDIV and AYLCB are shown by dashed arrow

AYLCB (Supplementary Fig. 2). Sequence analyses revealed the typical genome organization of the betasatellites including the satellite conserved region (SCR), the A-rich region, the $\beta \mathrm{C} 1$ gene and a predicted stem-loop structure with the conserved nonanucleotide sequence TAATATTAC as the origin of replication (Fig. 1D). Nucleotide sequences of the betasatellites were submitted to GenBank database under accession numbers MN240340 to MN240355 (Table 1).

Betasatellites have key roles in plant infection by the helper viruses (Saunders et al. 2004; Saeed et al. 2005; Tahir and Mansoor 2011; Hamza et al. 2018), including WDIV (Kumar et al. 2014a, b) and could be the reason for their maintenance by WDIV across India and Pakistan. To the best of our knowledge, this is the first report of presence of WDIV and AYLCB in wheat in Pakistan. Moreover, the presence and involvement of a betasatellite, AYLCB, in symptom severity of WDIV can have serious implications for the economic impact of the virus on crop yield. Considering the fact that WDIV and associated satellites are present in India and Pakistan, it will be interesting to examine the wheat samples from other regions in Asia for the presence of WDIV and associated DNA satellites. 
Acknowledgements Funding for the project was provided by the U.S. Department of Agriculture - Agricultural Research Service and the Minnesota State Agricultural Experiment Station. Mention of trade names or commercial products in this publication is solely for purpose of providing specific information and does not imply recommendation or endorsement by the US Department of Agriculture. USDA is an equal opportunity provider and employer.

\section{References}

Bull SE, Briddon RW, Markham PG (2003) Universal primers for the PCR-mediated amplification of DNA 1: a satellite-like molecule associated with begomovirus-DNA beta complexes. Mol Biotechnol 23(1):83-86

Edwards K, Johnstone C, Thompson C (1991) A simple and rapid method for the preparation of genomic plant DNA for PCR analysis. Nucleic Acids Res 19:1349

Hamza M, Tahir MN, Mustafa R, Kamal H, Khan MZ, Mansoor S, Briddon RW, Amin I (2018) Identification of a dicot infecting mastrevirus along with alpha- and betasatellite associated with leaf curl disease of spinach (Spinacia oleracea) in Pakistan. Virus Res 256:174-182

Huang X, Madan A (1999) CAP3: a DNA sequence assembly program. Genome Res 9:868-877

Kraberger S, Harkins GW, Kumari SG, Thomas JE, Schwinghamer MW, Sharman M, Collings DA, Briddon RW, Martin DP, Varsani A (2013) Evidence that dicot-infecting mastreviruses are particularly prone to inter-species recombination and have likely been circulating in Australia for longer than in Africa and the Middle East. Virology. 444(1-2):282-291
Kumar J, Kumar A, Roy JK, Tuli R, Khan JA (2010) Identification and molecular characterization of begomovirus and associated satellite DNA molecules infecting Cyamopsis tetragonoloba. Virus Genes 41:118-125

Kumar J, Singh SP, Kumar J, Tuli R (2012) A novel mastrevirus infecting wheat in India. Arch Virol 157:2031-2034

Kumar J, Kumar J, Singh SP, Tuli R (2014a) Association of satellites with a mastrevirus in natural infection: complexity of Wheat dwarf India virus disease. J Virol 88:7093-7104

Kumar J, Kumar J, Singh SP, Tuli R (2014b) $\beta C 1$ is a pathogenicity determinant: not only for begomoviruses but also for a mastrevirus. Arch Virol 159(11):3071-3076

Kumar J, Kumar J, Singh S, Shukla V, Singh SP, Tuli R (2015) Prevalence of wheat dwarf India virus in wheat in India. Curr Sci 108:260-265

Kumar S, Stecher G, Tamura K (2016) MEGA7: molecular evolutionary genetics analysis version 7.0 for bigger datasets. Mol Biol Evol 33: 1870-1874

Muhire B, Martin DP, Brown JK, Navas-Castillo J, Moriones E, Zerbini FM, Rivera-Bustamante R, Malathi VG, Briddon RW, Varsani A (2013) A genomewide pairwise-identity-based proposal for the classification of viruses in the genus Mastrevirus (family Geminiviridae). Arch Virol 158:1411-1424

Saeed M, Behjatnia SAA, Mansoor S, Zafar Y, Hasnain S, Rezaian MA (2005) A single complementary-sense transcript of a geminiviral DNA b satellite is determinant of pathogenicity. Mol PlantMicrobe Interact 18:7-14

Saunders K, Norman A, Gucciardo S, Stanley J (2004) The DNA $\beta$ satellite component associated with ageratum yellow vein disease encodes an essential pathogenicity protein $(\beta C 1)$. Virology. 324:37-47

Tahir MN, Mansoor S (2011) $\beta C 1$ of chili leaf curl betasatellite is a pathogenicity determinant. Virol J 8:509 